\title{
Catálogo de adaptaciones en el nuevo milenio: literatura y cine españoles (2001-2020) ${ }^{1}$
}

\author{
Rafael Malpartida Tirado \\ Universidad de Málaga \\ rmal@uma.es \\ ORCID ID: 0000-0001-8438-9014
}

Dos objetivos principales motivan la elaboración de este corpus filmográfico y explican su alcance cronológico y su disposición. En primer lugar, ya han sido estudiadas las principales adaptaciones de la Historia de nuestro cine, como las del franquismo analizadas en tres proyectos emprendidos por Pérez Bowie que abarcan las fases de la posguerra (2004), los cincuenta (2010) y el tardofranquismo (2013), o ya en la transición democrática y a lo largo de la década de los ochenta

\footnotetext{
${ }^{1}$ Este trabajo se encuadra en el Proyecto del Plan Propio de Investigación y Transferencia de la Universidad de Málaga Reescrituras de la novela en el cine y la ficción televisiva (2020-21). Al igual que el corpus bibliográfico publicado en este mismo número de Trasvases entre la literatura y el cine, tiene su origen en la actualización del $A L E C E$ por encargo del Centro Virtual Cervantes, que llevamos a cabo en 2013 un grupo de investigadores de la Universidad de Málaga y que finalmente no llegó a publicarse. Se incluye en el presente catálogo no solo la producción literaria española escrita en castellano, sino también en catalán, vasco y gallego (en cuyo caso se ha ofrecido el título bilingüe de cada adaptación). En cuanto al ámbito cinematográfico, se han excluido, en aras de una mayor homogeneidad, por una parte, los cortometrajes, y por otra, las coproducciones en las que España ha participado en menor medida - es el caso, por ejemplo, de La virgen de la lujuria, filme mexicano- y películas como Mar adentro, cuyas conexiones con la literatura — las cartas de Ramón Sampedro - son evidentes, pero que es considerada procedente de guion original y no adaptado, como refrendan los premios Goya de 2005, criterio este último de la Academia de las Artes y Ciencias Cinematográficas que se ha tenido en cuenta a la hora de elaborar la presente filmografía. En consecuencia, la fuente principal de este corpus ha sido la página web de la citada Academia, así como el catálogo on line del Instituto de la Cinematografía y de las Artes Audiovisuales, el libro de Heredero y Santamarina (2008) y las bases de datos Filmaffinity e $I M D b$. En caso de duda, se ha acudido al propio visionado de las películas, que constituye en última instancia la mejor fuente informativa, a través de sus títulos de crédito, para determinar cuáles adaptan un texto literario, en especial gracias a la excelente plataforma Filmin, que marca además con bastante precisión en forma de tag la procedencia literaria de sus títulos.
} 
y los noventa (Jaime, 2000). Si estos acercamientos críticos han sido sobresalientes, a menudo nuestras adaptaciones han propiciado otros trabajos poco afortunados por deslizarse hacia el improductivo fidelity criticism, como han alertado, entre otros, Zecchi (2012) y Stam (2014). Como la corriente parece activarse sobre todo cuando de trata de obras canónicas, tal vez convenga un giro hacia casos menos conocidos. Así podría renovarse metodológicamente este ámbito de estudio, bien porque aún no han ingresado en el canon muchos de los textos literarios en que se basan — de manera que la tentación de exigirles a las películas una adecuación a sus fuentes se reduce considerablemente - bien porque es aún tan escasa la atención crítica que han recibido muchas de estas adaptaciones por una simple razón temporal, que permiten una exégesis prácticamente inédita.

De ahí la ordenación cronológica de este listado de películas: no solo se abren nuevas perspectivas en cuanto a obras particulares, sino que la evolución de la dinámica adaptadora en el nuevo milenio se nos aparece en su devenir, con contraste significativo frente a etapas anteriores. Esta presentación, a su vez, potencia el estudio diacrónico pero también apunta a la atención particular a autores y títulos - tanto literarios como fílmicos- - dado que su formato electrónico propicia sencillas búsquedas por todo el documento.

Esta otra dimensión ofrece, de entrada, datos estadísticos como el hecho de que el autor que más figura en este corpus del nuevo milenio sea Cervantes, igual que lo era en la centuria anterior solo detrás de Galdós, pero teniendo en cuenta que la mayoría de las más recientes recreaciones del Quijote parten de una simple inspiración, de forma que nos encontramos en el terreno de la mitocrítica (Pardo, 2011) y no de la transposición en sentido estricto, son otros literatos muy conocidos los que lideran el ranking de adaptaciones. Son así Arturo PérezReverte, Bernardo Atxaga, Lorenzo Silva y Dolores Redondo - en cabeza con tres entradas-, y Federico García Lorca, Rafael Azcona, Juan Marsé, Elvira Lindo, Almudena Grandes, Lucía Etxebarria, Manuel Rivas y Fernando Marías - a continuación con dos - los que se encaraman a los primeros puestos, de modo que las nuevas tendencias incluyen a autores "asentados", pero asimismo a otros más recónditos como Isaac Rosa y Jordi Galcerán — de quienes hay tres adaptaciones, así que figuran ex aequo en primer lugar- o Jordi Casanovas y Emilio Ruiz Barrachina - a la zaga con dos-, que podrían despertar mayor atención crítica e incluso en forma de estudio panorámico, dado que el trasvase al cine se ha producido en varias 
ocasiones, en el caso del último mediante autoadaptación ${ }^{2}$. Que sea esta la exigua nómina de autores adaptados más de una vez revela, por otra parte, una notable dispersión a la hora de elegir fuentes de inspiración literaria. Y que varios de los textos adaptados sean inéditos, en especial en la esfera teatral, es otro de los datos novedosos que se desprenden de este corpus y que permiten comparar con las tendencias de la anterior centuria. Ambas circunstancias, desde luego, apuntan a una cierta "descanonización" de las prácticas adaptativas, ya que irrumpen autores poco conocidos e incluso textos que han viajado al cine antes que a la propia página impresa ${ }^{3}$.

En segundo lugar, la reivindicación del guion adaptado como "punto de encuentro" entre la literatura y el cine (Malpartida Tirado, 2015: 142-144) merece que se destaque no solo a sus artífices — para apreciar, por ejemplo, en qué casos recaen la dirección del filme y su escritura en la misma persona, o en qué otros asume el oficio de guionista el propio literato, ya sea junto a un profesional o como tentativa en solitario de un nuevo tipo de práctica-, sino también sus ediciones, con las que se puede beneficiar el cotejo introduciendo un elemento que a menudo se ha soslayado en el estudio comparado entre literatura y cine. Ambos aspectos figuran en la cuarta columna del listado y se remite tanto a las exhumaciones tradicionales como a las que ha realizado en formato electrónico la Academia de Cine, iniciativa esta última muy de agradecer para los que nos hemos interesado por el guion adaptado.

\footnotetext{
${ }^{2}$ Este fenómeno se ha incrementado de manera extraordinaria merced a que los vasos comunicantes entre literatura y cine (empezando por la participación del literato en el guion adaptado) han sido más activos en los últimos años. Ejemplos de autoadaptaciones en el nuevo milenio son Tánger de Juan Madrid, El rey tuerto de Marc Crehuet, La llamada de Javier Ambrossi y Javier Calvo, El rey de Alberto San Juan, Sentimental de Cesc Gay y La suite nupcial de Carlos Iglesias. Que la mayoría de ellas se circunscriban al ámbito teatral revela que los textos pueden trasladarse a ambos medios indistintamente y en poco tiempo, en un cruce de escrituras y oficios (dramaturgos que practican el cine, cineastas que practican la dramaturgia) que nunca había resultado tan fecundo en nuestras letras.

${ }^{3}$ Trasvase este último que ya se está produciendo cada vez más en los últimos años con el propio teatro, llevado a las tablas sin que se haya publicado la obra. Resulta revelador de estos nuevos engranajes, alejados de la secuencia lógica tradicional (texto literario-representación teatral-adaptación al cine), que varias de las últimas adaptaciones se hayan difundido en su versión escrita solo a través del guion cinematográfico alojado en la web de la Academia de Cine, ya que no han llegado a publicarse como obras literarias autónomas por parte de una editorial.
} 
Es, por tanto, el incentivo de nuevos trabajos - tanto de Fin de Grado, Fin de Máster y doctorales, por una parte, como de crítica especializada, por otra - sobre nuestras adaptaciones de los últimos veinte años lo que nos conduce a mostrar este corpus, máxime ahora que una revista muy joven como Trasvases entre la literatura y el cine aspira a promover perspectivas diferentes en este campo de investigación, empezando por nuestra cinematografía pero con la confianza en que otros corpus similares que recojan la producción de otros países aparecerán en futuros números. Sirva esta entrega inaugural, por tanto, como llamamiento para emprender dicha tarea y que así la necesaria renovación del corpus de estudio en este ámbito de investigación vaya desarrollándose en el espacio que brindamos desde Trasvases entre la literatura y el cine. 


\begin{tabular}{|c|c|c|c|c|c|}
\hline Año & Película & Dirección & Guion & Texto literario & $\begin{array}{c}\text { Autor/a } \\
\text { literario/a }\end{array}$ \\
\hline 2001 & Juana la Loca & Vicente Aranda & Vicente Aranda y Antonio Larreta & La locura de amor & $\begin{array}{c}\text { Manuel Tamayo } \\
\text { y Baus }\end{array}$ \\
\hline 2001 & Son de mar & Bigas Luna & Rafael Azcona & Homónimo & Manuel Vicent \\
\hline 2001 & El bosque animado & $\begin{array}{c}\text { Ángel de la Cruz y } \\
\text { Manolo Gómez }\end{array}$ & Ángel de la Cruz & Homónimo & $\begin{array}{l}\text { Wenceslao } \\
\text { Fernández Flórez }\end{array}$ \\
\hline 2001 & $\begin{array}{l}\text { Manolito Gafotas en } \\
\text { ¡Mola ser jefe! }\end{array}$ & Joan Potau & $\begin{array}{l}\text { Salvador Maldonado, Joan } \\
\text { Potau y Cecilia Bartolomé }\end{array}$ & ¡Cómo molo! & Elvira Lindo \\
\hline 2001 & Lázaro de Tormes & $\begin{array}{l}\text { Fernando Fernán } \\
\text { Gómez y José Luis } \\
\text { García Sánchez }\end{array}$ & Fernando Fernán Gómez & $\begin{array}{l}\text { E1 lazarillo de } \\
\text { Tormes }\end{array}$ & Anónimo \\
\hline 2001 & $\begin{array}{l}\text { Amor, curiosidad, } \\
\text { prozak y dudas }\end{array}$ & Miguel Santesmases & $\begin{array}{c}\text { Miguel Santesmases y Lucía } \\
\text { Etxebarria }\end{array}$ & $\begin{array}{l}\text { Amor, curiosidad, } \\
\text { prozac y dudas }\end{array}$ & Lucía Etxebarria \\
\hline 2001 & Salvajes & Carlos Molinero & $\begin{array}{c}\text { Jorge Juan Martínez, Carlos } \\
\text { Molinero, Clara Pérez Escrivá } \\
\text { y Salvador Maldonado } \\
\text { (editado en Ocho y Medio } \\
\text { junto a la obra de teatro) }\end{array}$ & Homónimo & $\begin{array}{c}\text { José Luis Alonso } \\
\text { de Santos }\end{array}$ \\
\hline 2001 & $\begin{array}{l}\text { La isla del holandés } \\
\text { (L'illa de l'holandès) }\end{array}$ & Sigfrid Monleón & Sigfrid Monleón & Homónimo & Ferran Torrent \\
\hline 2001 & $\begin{array}{c}\text { El paraíso ya no es lo } \\
\text { que era }\end{array}$ & Francesc Betriú & Rafael Azcona & $\begin{array}{l}\text { Homónimo } \\
\text { (cuento) }\end{array}$ & $\begin{array}{l}\text { Carmen Rico- } \\
\text { Godoy }\end{array}$ \\
\hline 2001 & Todo me pasa a mí & $\begin{array}{l}\text { Miquel García } \\
\text { Borda }\end{array}$ & Miquel García Borda & Canvis & Toni Martín \\
\hline 2001 & $\begin{array}{l}\text { Hermanas de sangre } \\
\text { (Germanes de sang) }\end{array}$ & Jesús Garay & $\begin{array}{c}\text { Maite Carranza y Teresa } \\
\text { Vilardell }\end{array}$ & Homónimo & $\begin{array}{c}\text { Cristina } \\
\text { Fernández Cubas }\end{array}$ \\
\hline 2001 & $\begin{array}{c}\text { Amar y morir en } \\
\text { Sevilla (Don Juan } \\
\text { Tenorio) }\end{array}$ & Víctor Alcázar & Aitor Aguirre & Don Juan Tenorio & José Zorrilla \\
\hline 2001 & $\begin{array}{l}\text { Anita no pierde el tren } \\
\text { (Anita no perd el tren) }\end{array}$ & Ventura Pons & Ventura Pons & Bones obres & $\begin{array}{l}\text { Lluís-Anton } \\
\text { Baulenas }\end{array}$ \\
\hline
\end{tabular}




\begin{tabular}{|c|c|c|c|c|c|}
\hline 2002 & $\begin{array}{c}\text { Cásate conmigo, } \\
\text { Maribel }\end{array}$ & Ángel Blasco & Ángel Blasco & $\begin{array}{l}\text { Maribel y la } \\
\text { extraña familia }\end{array}$ & Miguel Mihura \\
\hline 2002 & $\begin{array}{l}\text { El alquimista } \\
\text { impaciente }\end{array}$ & Patricia Ferreira & $\begin{array}{l}\text { Patricia Ferreira y Enrique } \\
\text { Jiménez }\end{array}$ & Homónimo & Lorenzo Silva \\
\hline 2002 & $\begin{array}{c}\text { El caballero Don } \\
\text { Quijote }\end{array}$ & $\begin{array}{l}\text { Manuel Gutiérrez } \\
\text { Aragón }\end{array}$ & Manuel Gutiérrez Aragón & $\begin{array}{c}\text { Don Quijote de la } \\
\text { Mancha }\end{array}$ & $\begin{array}{l}\text { Miguel de } \\
\text { Cervantes }\end{array}$ \\
\hline 2002 & $\begin{array}{l}\text { El embrujo de } \\
\text { Shanghai }\end{array}$ & Fernando Trueba & Fernando Trueba & $\begin{array}{l}\text { El embrujo de } \\
\text { Shanghai }\end{array}$ & Juan Marsé \\
\hline 2002 & El florido pensil & Juan José Porto & $\begin{array}{c}\text { Juan José Porto, Roberto } \\
\text { Oltra y Roberto Vera }\end{array}$ & Homónimo & Andrés Sopeña \\
\hline 2002 & La soledad era esto & Sergio Renán & $\begin{array}{c}\text { Manuel Matji, Aida Bortnik, } \\
\text { Sergio Renán }\end{array}$ & Homónimo & Juan José Millás \\
\hline 2002 & Nos miran & $\begin{array}{c}\text { Norberto López } \\
\text { Amado }\end{array}$ & $\begin{array}{l}\text { Jorge Guerricaechevarría } \\
\text { (editado en Ocho y Medio) }\end{array}$ & Los otros & $\begin{array}{l}\text { Javier García } \\
\text { Sánchez }\end{array}$ \\
\hline 2002 & Primer y último amor & $\begin{array}{l}\text { Antonio Giménez } \\
\text { Rico }\end{array}$ & Antonio Giménez Rico & Homónimo & $\begin{array}{c}\text { Torcuato Luca de } \\
\text { Tena }\end{array}$ \\
\hline 2002 & Volverás & Antonio Chavarrías & $\begin{array}{c}\text { Antonio Chavarrías } \\
\text { (editado en Ocho y Medio) }\end{array}$ & $\begin{array}{l}\text { Un enano español } \\
\text { se suicida en Las } \\
\text { Vegas }\end{array}$ & $\begin{array}{l}\text { Francisco } \\
\text { Casavella }\end{array}$ \\
\hline 2002 & El viaje de Carol & Imanol Uribe & $\begin{array}{c}\text { Ángel García Roldán e Imanol } \\
\text { Uribe (editado en Ocho y } \\
\text { Medio) }\end{array}$ & A boca de noche & $\begin{array}{l}\text { Ángel García } \\
\text { Roldán }\end{array}$ \\
\hline 2002 & La tarara del chapao & $\begin{array}{l}\text { Enrique Navarro } \\
\text { Monje }\end{array}$ & $\begin{array}{c}\text { Toni Canet, Enrique Navarro } \\
\text { Monje, Carles Pons }\end{array}$ & Chapao & Carles Pons \\
\hline 2003 & Besos de gato & Rafael Alcázar & $\begin{array}{c}\text { Rafael Alcázar, Felipe } \\
\text { Hernández Cava y Beda } \\
\text { Docampo Feijóo }\end{array}$ & Falso movimiento & $\begin{array}{l}\text { Alejandro } \\
\text { Gándara }\end{array}$ \\
\hline 2003 & Diario de una becaria & Josetxo San Mateo & Ricardo Luis González & Homónimo & Nacho Abad \\
\hline 2003 & El lápiz del carpintero & Antón Reixa & Antón Reixa y Xosé Morais & Homónimo & Manuel Rivas \\
\hline 2003 & El misterio Galíndez & Gerardo Herrero & $\begin{array}{l}\text { Luis Marías y Ángeles } \\
\text { González-Sinde }\end{array}$ & Homónimo & $\begin{array}{c}\text { Manuel Vázquez } \\
\text { Montalbán }\end{array}$ \\
\hline
\end{tabular}




\begin{tabular}{|c|c|c|c|c|c|}
\hline 2003 & $\begin{array}{l}\text { La flaqueza del } \\
\text { bolchevique }\end{array}$ & $\begin{array}{c}\text { Manuel Martín } \\
\text { Cuenca }\end{array}$ & $\begin{array}{l}\text { Manuel Martín Cuenca y } \\
\text { Lorenzo Silva (editado en } \\
\text { Lagartos Editores) }\end{array}$ & Homónimo & Lorenzo Silva \\
\hline 2003 & La luz prodigiosa & Miguel Hermoso & $\begin{array}{c}\text { Fernando Marías (editado en } \\
\text { Ocho y Medio) }\end{array}$ & Homónimo & Fernando Marías \\
\hline 2003 & $\begin{array}{l}\text { Lo mejor que le puede } \\
\text { pasar a un cruasán }\end{array}$ & Paco Mir & Paco Mir & Homónimo & Pablo Tusset \\
\hline 2003 & Los novios búlgaros & Eloy de la Iglesia & $\begin{array}{c}\text { Fernando Guillén Cuervo, } \\
\text { Eloy de la Iglesia y Antonio } \\
\text { Hens }\end{array}$ & Homónimo & $\begin{array}{l}\text { Eduardo } \\
\text { Mendicutti }\end{array}$ \\
\hline 2003 & Pacto de Brujas & Javier Elorrieta & $\begin{array}{c}\text { Javier Elorrieta, J. Antonio } \\
\text { Porto y Frank Palacios }\end{array}$ & La camisa del revés & Andreu Martín \\
\hline 2003 & Palabras encadenadas & Laura Mañá & Fernando de Felipe & Homónimo & Jordi Galcerán \\
\hline 2003 & Planta $4^{a}$ & Antonio Mercero & $\begin{array}{l}\text { Antonio Mercero, Albert } \\
\text { Espinosa e Ignacio del Moral } \\
\text { (editado en Ocho y Medio) }\end{array}$ & $\begin{array}{l}\text { Los pelones } \\
\text { (inédito) }\end{array}$ & Albert Espinosa \\
\hline 2003 & Soldados de Salamina & David Trueba & David Trueba & Homónimo & Javier Cercas \\
\hline 2003 & Trece campanadas & Xavier Villaverde & $\begin{array}{l}\text { Curro Royo, Juan Vicente } \\
\text { Pozuelo y Xavier Villaverde } \\
\text { (editado en Ocho y Medio) }\end{array}$ & Homónimo & Suso de Toro \\
\hline 2003 & Valentín & Juan Luis Iborra & Juan Luis Iborra y Marc Cases & Homónimo & Juan Gil-Albert \\
\hline 2004 & El año del diluvio & Jaime Chávarri & $\begin{array}{c}\text { Eduardo Mendoza y Jaime } \\
\text { Chávarri }\end{array}$ & Homónimo & $\begin{array}{l}\text { Eduardo } \\
\text { Mendoza }\end{array}$ \\
\hline 2004 & Hipnos & David Carreras Solè & $\begin{array}{l}\text { David Carreras Solè y Juan } \\
\text { Manuel Ruiz Córdoba }\end{array}$ & Homónimo & Javier Azpeitia \\
\hline 2004 & $\begin{array}{l}\text { A la sombra de los } \\
\text { sueños }\end{array}$ & $\begin{array}{l}\text { Emilio Ruiz } \\
\text { Barrachina }\end{array}$ & $\begin{array}{l}\text { Emilio Ruiz Barrachina, Carlos } \\
\text { La Rosa y Francisco Aguirre }\end{array}$ & Homónimo & $\begin{array}{l}\text { Emilio Ruiz } \\
\text { Barrachina }\end{array}$ \\
\hline 2004 & Tánger & Juan Madrid & $\begin{array}{l}\text { Juan Madrid (editado en Ocho } \\
\text { y Medio) }\end{array}$ & Homónimo & Juan Madrid \\
\hline 2004 & Yo, puta & Luna (María Lidón) & Isabel Pisano y Adela Ibáñez & Homónimo & Isabel Pisano \\
\hline 2004 & Romasanta & Paco Plaza & Elena Serra y Alberto Marini & $\begin{array}{l}\text { Romasanta. } \\
\text { Memorias inciertas } \\
\text { de un hombre lobo }\end{array}$ & Alfredo Conde \\
\hline
\end{tabular}




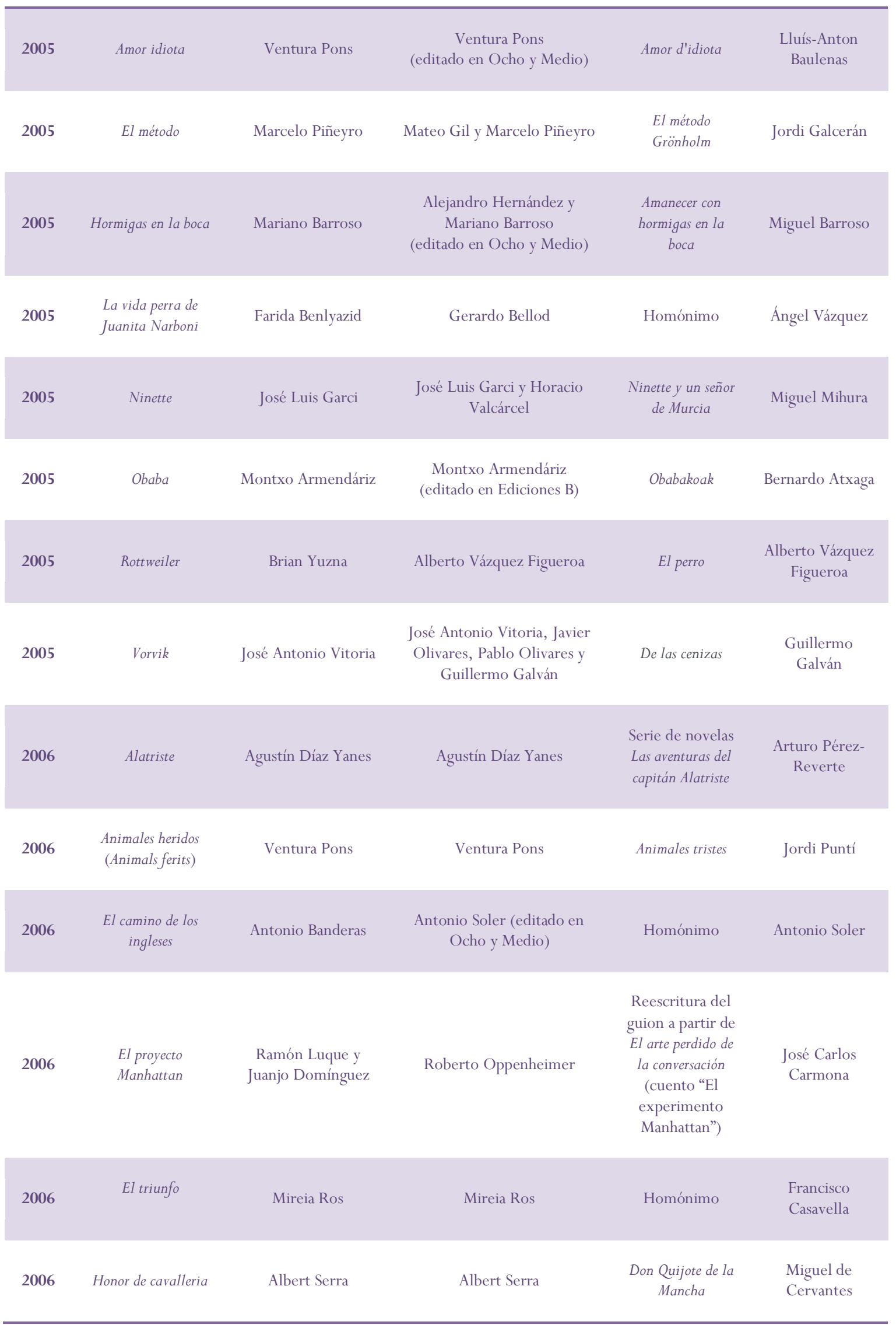




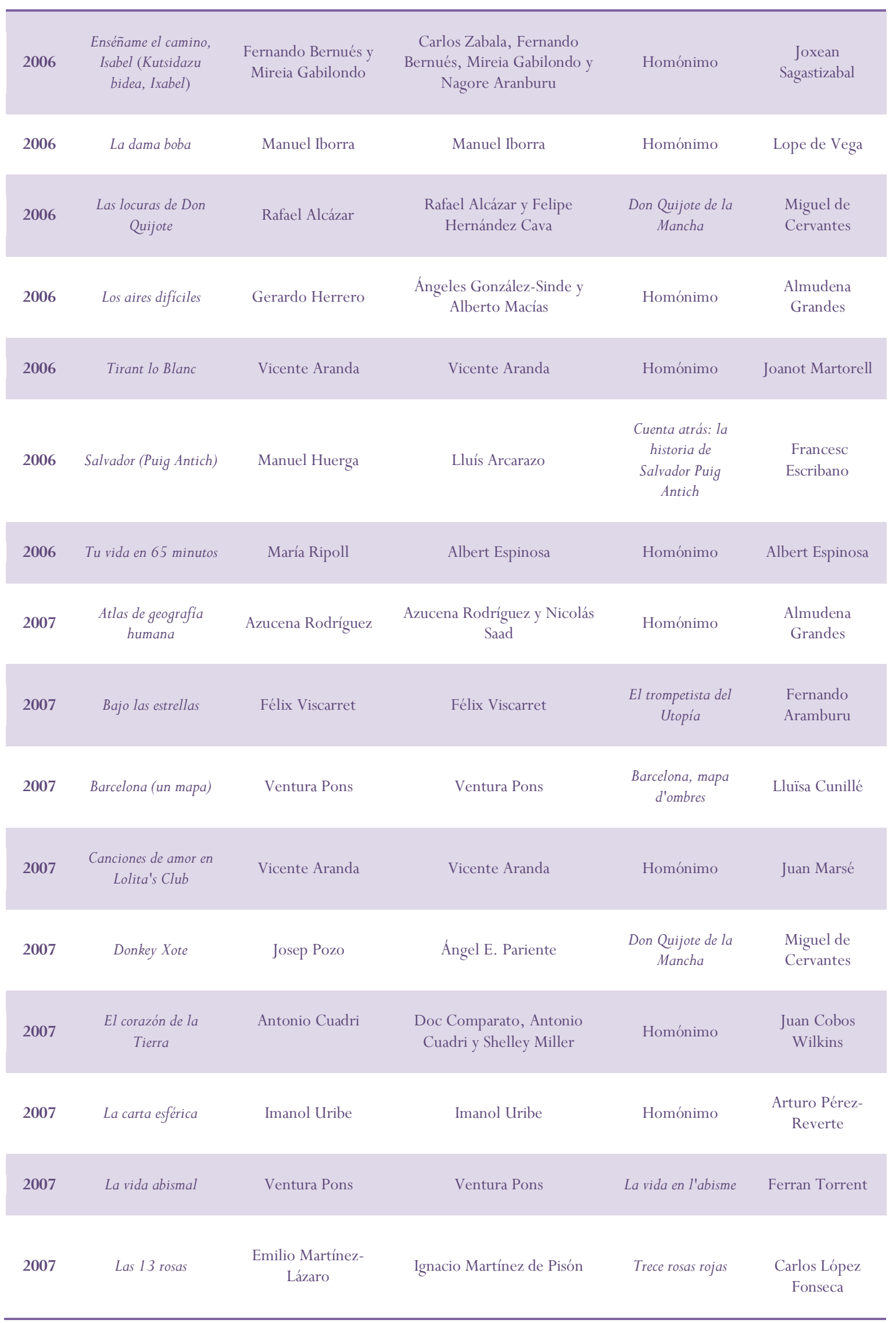




\begin{tabular}{|c|c|c|c|c|c|}
\hline 2007 & Luz de domingo & José Luis Garci & $\begin{array}{c}\text { José Luis Garci y Horacio } \\
\text { Valcárcel }\end{array}$ & Homónimo & $\begin{array}{c}\text { Ramón Pérez de } \\
\text { Ayala }\end{array}$ \\
\hline 2008 & $\begin{array}{c}\text { Bendito Canalla, la } \\
\text { verdadera historia de } \\
\text { Genarín }\end{array}$ & Nacho Chueca & Nacho Chueca & $\begin{array}{l}\text { El entierro de } \\
\text { Genarín }\end{array}$ & Julio Llamazares \\
\hline 2008 & $\begin{array}{l}\text { Diario de una } \\
\text { ninfómana }\end{array}$ & Christian Molina & Cuca Canals & Homónimo & Valérie Tasso \\
\hline
\end{tabular}

\section{Las manos del pianista}

(TV)
Sergio G. Sánchez
Miguel Barros, Eugenio
Fuentes, Kike Maíllo y Sergio

G. Sánchez

\begin{tabular}{|c|c|c|c|c|c|}
\hline 2008 & El juego del ahorcado & $\begin{array}{c}\text { Manuel Gómez } \\
\text { Pereira }\end{array}$ & $\begin{array}{c}\text { Manuel Gómez Pereira y } \\
\text { Salvador García Ruiz }\end{array}$ & Homónimo & Imma Turbau \\
\hline 2008 & El libro de las aguas & $\begin{array}{l}\text { Antonio Giménez } \\
\text { Rico }\end{array}$ & $\begin{array}{c}\text { Antonio Giménez Rico y Joan } \\
\text { Álvarez }\end{array}$ & Homónimo & $\begin{array}{c}\text { Alejandro López } \\
\text { Andrada }\end{array}$ \\
\hline 2008 & $\begin{array}{l}\text { Forasteros } \\
\text { (Forasters) }\end{array}$ & Ventura Pons & Ventura Pons & Homónimo & Sergi Belbel \\
\hline 2008 & La vida en rojo & Andrés Linares & Andrés Linares e Isaac Rosa & El vano ayer & Isaac Rosa \\
\hline
\end{tabular}

2008 Sangre de mayo $\quad$ José Luis Garci $\quad$ José Luis Garci y Horacio $\begin{gathered}\text { El } 19 \text { de marzo y el } \\ 2 \text { de mayo } \\ \text { (Episodios } \\ \text { nacionales) }\end{gathered}$

\begin{tabular}{|c|c|c|c|c|c|}
\hline 2008 & Un poco de chocolate & Aitzol Aramaio & $\begin{array}{c}\text { Aitzol Aramaio y Michel } \\
\text { Gaztambide }\end{array}$ & Un tranvía en $S P$ & Unai Elorriaga \\
\hline 2008 & Una palabra tuya & $\begin{array}{l}\text { Ángeles González- } \\
\text { Sinde }\end{array}$ & Ángeles González-Sinde & Homónimo & Elvira Lindo \\
\hline 2009 & A la deriva & Ventura Pons & Ventura Pons & Homónimo & $\begin{array}{l}\text { Lluís-Anton } \\
\text { Baulenas }\end{array}$ \\
\hline 2009 & Castillos de cartón & $\begin{array}{c}\text { Salvador García } \\
\text { Ruiz }\end{array}$ & Enrique Urbizu & Homónimo & $\begin{array}{l}\text { Almudena } \\
\text { Grandes }\end{array}$ \\
\hline 2009 & Celda 211 & Daniel Monzón & $\begin{array}{c}\text { Daniel Monzón y Jorge } \\
\text { Guerricaechevarría }\end{array}$ & Homónimo & $\begin{array}{c}\text { Francisco Pérez } \\
\text { Gandul }\end{array}$ \\
\hline
\end{tabular}




\begin{tabular}{|c|c|c|c|c|c|}
\hline 2009 & El cónsul de Sodoma & Sigfrid Monleón & $\begin{array}{c}\text { Sigfrid Monleón, Joaquín } \\
\text { Górriz y Miguel Angel } \\
\text { Fernández }\end{array}$ & $\begin{array}{l}\text { Jaime Gil de } \\
\text { Biedma }\end{array}$ & Miguel Dalmau \\
\hline 2009 & $\begin{array}{l}\text { V.O.S. (Versión } \\
\text { original subtitulada) }\end{array}$ & Cesc Gay & Cesc Gay & Homónimo & Carol López \\
\hline 2010 & $\begin{array}{c}\text { Don Mendo Rock. ¿La } \\
\text { venganza? }\end{array}$ & $\begin{array}{l}\text { José Luis García } \\
\text { Sánchez }\end{array}$ & $\begin{array}{l}\text { José Luis García Sánchez y } \\
\text { José Luis Alonso de Santos }\end{array}$ & $\begin{array}{l}\text { La venganza de } \\
\text { don Mendo }\end{array}$ & $\begin{array}{l}\text { Pedro Muñoz } \\
\text { Seca }\end{array}$ \\
\hline 2010 & El diario de Carlota & $\begin{array}{l}\text { José Manuel } \\
\text { Carrasco }\end{array}$ & $\begin{array}{c}\text { Roberto Santiago, Ángela } \\
\text { Armero y José Manuel } \\
\text { Carrasco }\end{array}$ & $\begin{array}{l}\text { El diario rojo de } \\
\text { Carlota }\end{array}$ & Gemma Lienas \\
\hline 2010 & El idioma imposible & Rodrigo Rodero & $\begin{array}{l}\text { Rodrigo Rodero y Michel } \\
\text { Gaztambide }\end{array}$ & Homónimo & $\begin{array}{l}\text { Francisco } \\
\text { Casavella }\end{array}$ \\
\hline 2010 & Elisa $K$ & $\begin{array}{l}\text { Judith Colell y Jordi } \\
\text { Cadena }\end{array}$ & Jordi Cadena & Elisa Kiseljak & Lolita Bosch \\
\hline 2010 & $\begin{array}{l}\text { Las aventuras de Don } \\
\text { Quijote }\end{array}$ & Antonio Zurera & Antonio Zurera & $\begin{array}{c}\text { Don Quijote de la } \\
\text { Mancha }\end{array}$ & $\begin{array}{l}\text { Miguel de } \\
\text { Cervantes }\end{array}$ \\
\hline 2010 & $\begin{array}{l}\text { Pan negro } \\
(\text { Pa negre })\end{array}$ & Agustí Villaronga & Agustí Villaronga & Homónimo & Emili Teixidor \\
\hline 2010 & El discípulo & $\begin{array}{l}\text { Emilio Ruiz } \\
\text { Barrachina }\end{array}$ & Emilio Ruiz Barrachina & $\begin{array}{c}\text { Yo, Juan, el } \\
\text { discípulo amado }\end{array}$ & $\begin{array}{l}\text { Rafael Esteban } \\
\text { Poullet }\end{array}$ \\
\hline 2011 & $\begin{array}{l}\text { Dos hermanos } \\
\qquad \text { (Bi anai) }\end{array}$ & Imanol Rayo & Imanol Rayo & Homónimo & Bernardo Atxaga \\
\hline 2011 & La voz dormida & Benito Zambrano & $\begin{array}{c}\text { Benito Zambrano e Ignacio del } \\
\text { Moral }\end{array}$ & Homónimo & Dulce Chacón \\
\hline 2011 & Arrugas & Ignacio Ferreras & $\begin{array}{c}\text { Ángel de la Cruz, Paco } \\
\text { Roca, Ignacio Ferreras } \\
\text { y Rosanna Cecchini }\end{array}$ & Homónimo & Paco Roca \\
\hline 2011 & $\begin{array}{l}\text { La soledad del triunfo } \\
\text { (TV) }\end{array}$ & Álvaro de Armiñán & $\begin{array}{c}\text { Antonio Onetti y Ana López- } \\
\text { Souza }\end{array}$ & Homónimo & $\begin{array}{l}\text { Rafael Moreno } \\
\text { Cereijo }\end{array}$ \\
\hline 2011 & $\begin{array}{l}\text { Los muertos no se } \\
\text { tocan, nene }\end{array}$ & $\begin{array}{c}\text { José Luis García } \\
\text { Sánchez }\end{array}$ & $\begin{array}{c}\text { José Luis García Sánchez, } \\
\text { Bernardo Sánchez y David } \\
\text { Trueba }\end{array}$ & Homónimo & Rafael Azcona \\
\hline 2011 & $\begin{array}{l}\text { Mil cretinos } \\
(\text { Mil cretins })\end{array}$ & Ventura Pons & Ventura Pons & Homónimo & Quim Monzó \\
\hline
\end{tabular}




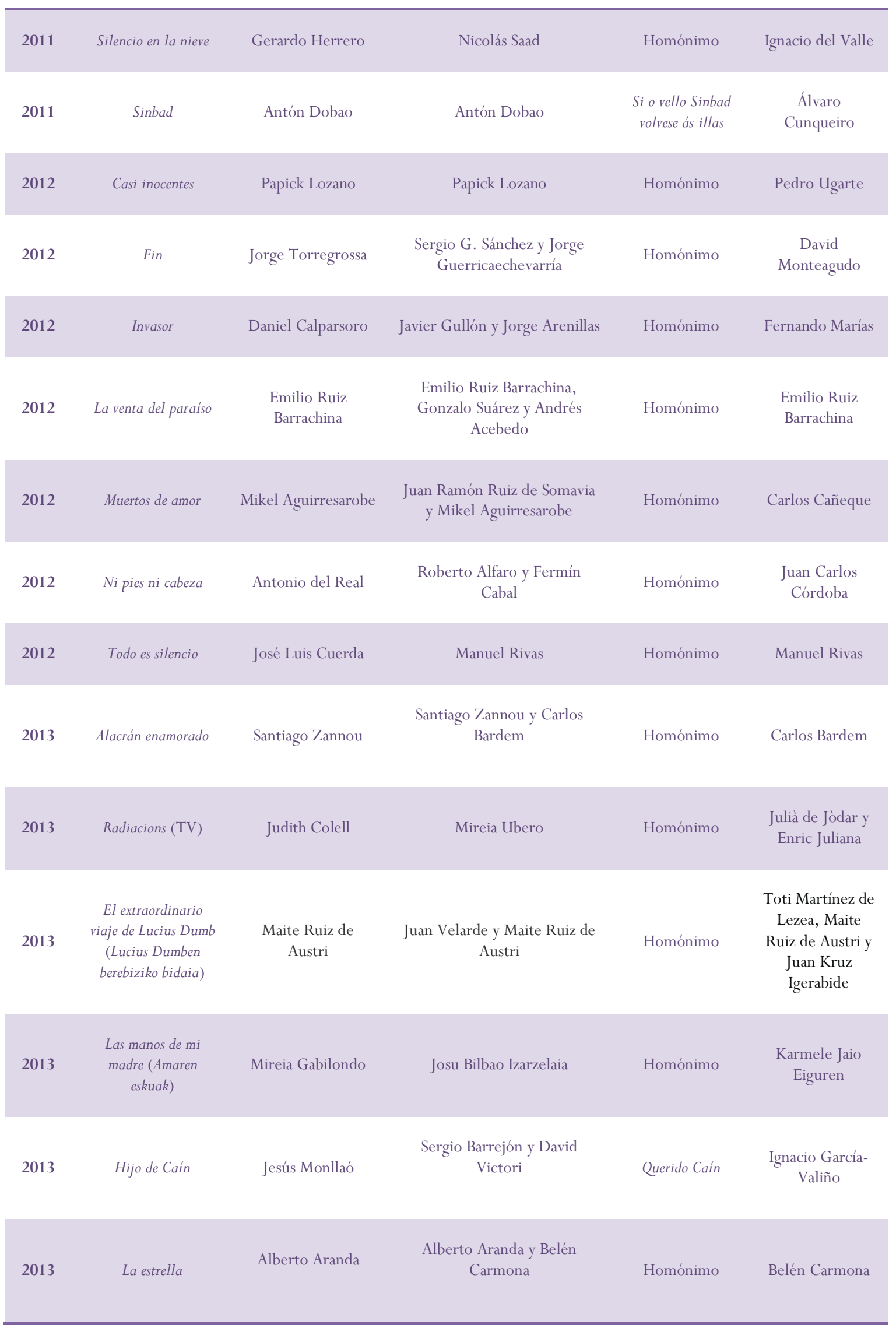




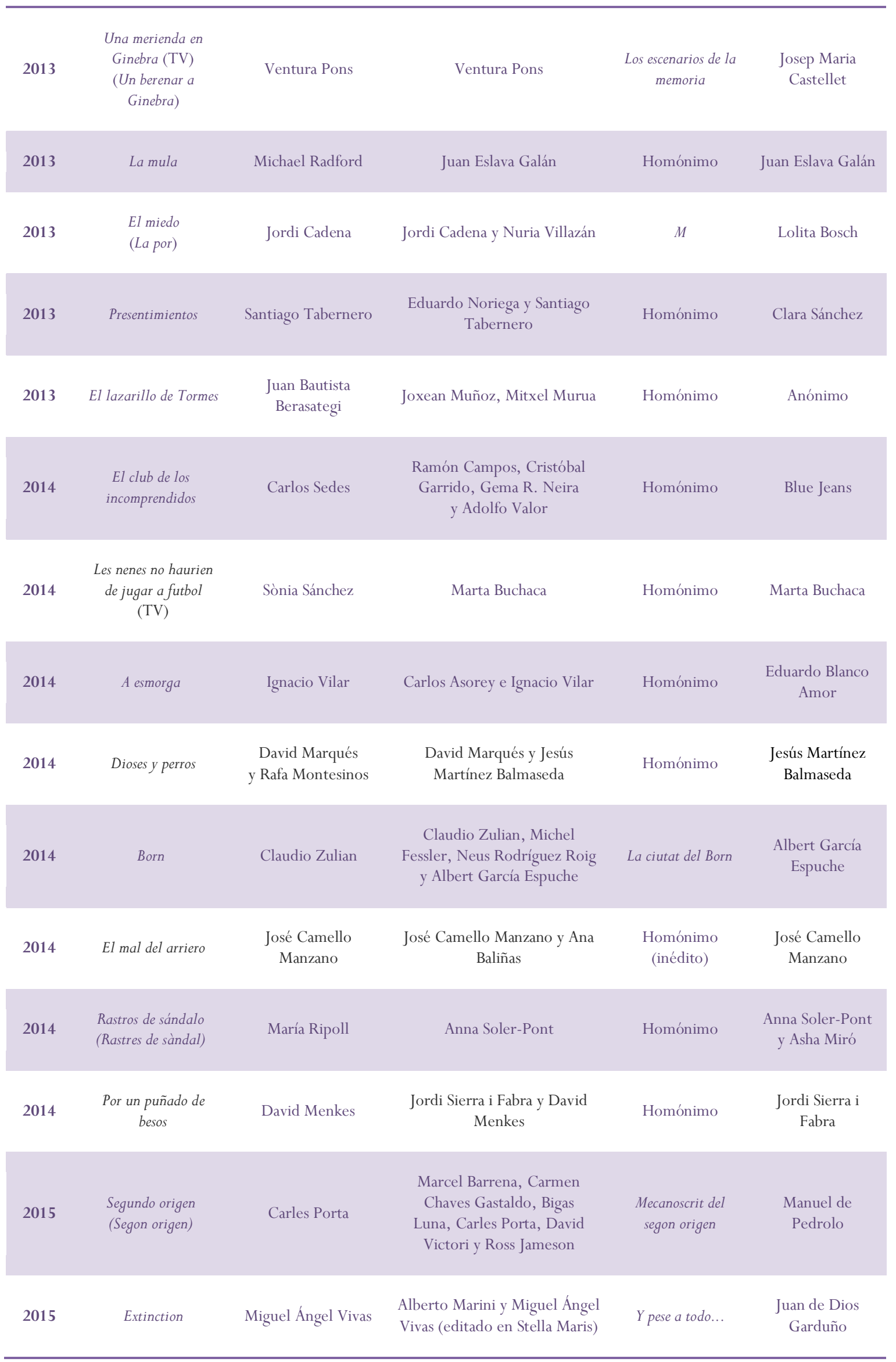




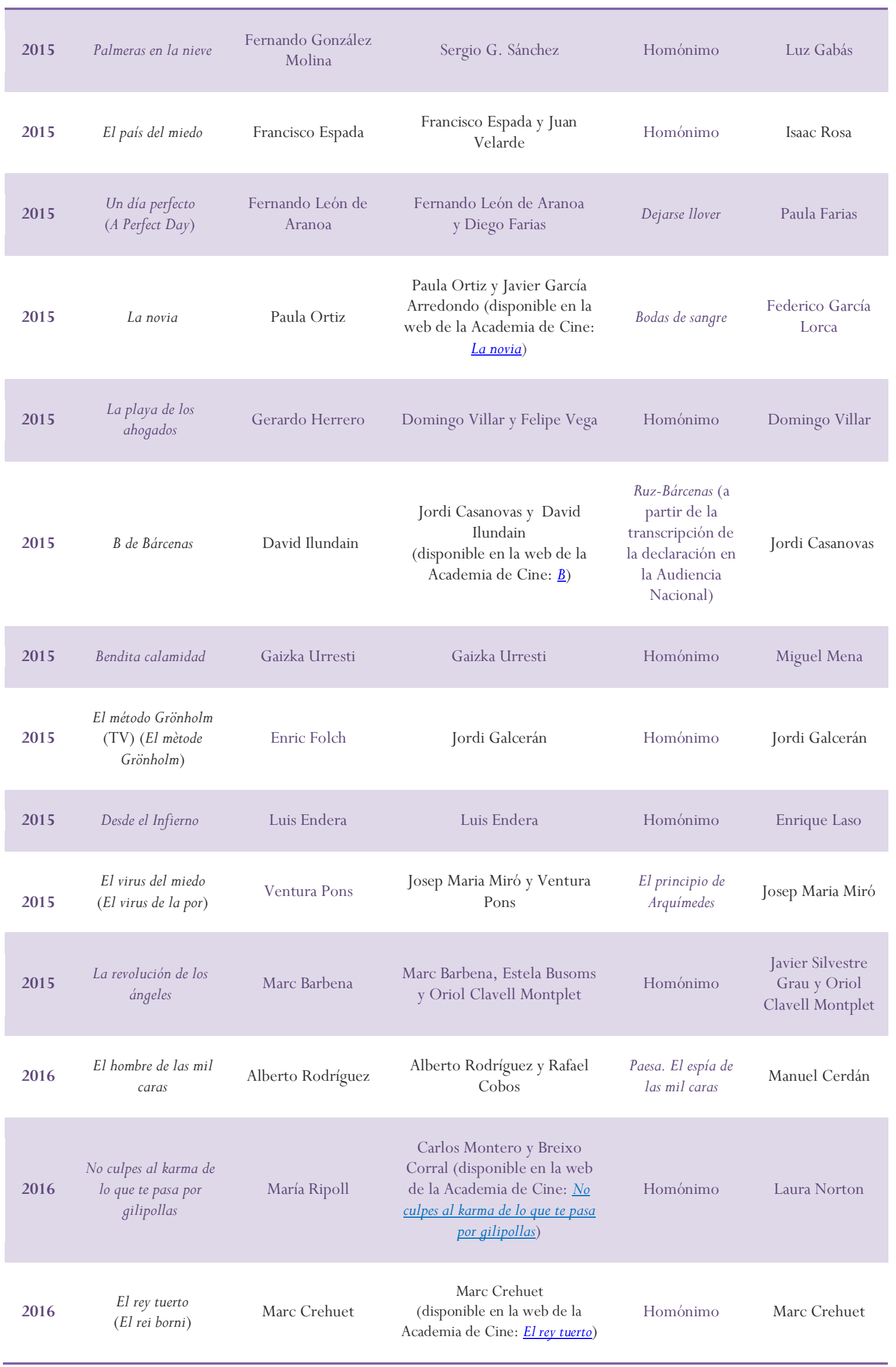




\begin{tabular}{|c|c|c|c|c|c|}
\hline 2016 & La punta del iceberg & David Cánovas & $\begin{array}{c}\text { David Cánovas, José Amaro } \\
\text { Carrillo y Alberto García } \\
\text { Martín }\end{array}$ & Homónimo & Antonio Tabares \\
\hline 2016 & Acantilado & Helena Taberna & $\begin{array}{c}\text { Helena Taberna, Natxo López } \\
\text { y Andrés Martorell } \\
\text { (disponible en la web de la } \\
\text { Academia de Cine: } \underline{\text { El contenido }} \\
\text { del silencio) }\end{array}$ & $\begin{array}{l}\text { El contenido del } \\
\text { silencio }\end{array}$ & Lucía Etxebarria \\
\hline 2016 & $\begin{array}{l}\text { Cenizas } \\
\text { (Lapols) }\end{array}$ & Llàtzer Garcia & $\begin{array}{l}\text { Llàtzer Garcia (disponible en } \\
\text { la web de la Academia de } \\
\text { Cine: } \underline{\underline{L a} \text { pols }} \text { ) }\end{array}$ & Homónimo & Llàtzer Garcia \\
\hline 2016 & La mano invisible & David Macián & $\begin{array}{c}\text { David Macián y Daniel } \\
\text { Cortázar }\end{array}$ & Homónimo & Isaac Rosa \\
\hline 2016 & 22 ángeles (TV) & Miguel Bardem & Alicia Luna & Ángeles custodios & $\begin{array}{l}\text { Almudena de } \\
\text { Arteaga }\end{array}$ \\
\hline 2016 & Laia (TV) & Lluís Danés & Lluís Arcarazo y María Jaén & Homónimo & Salvador Espriu \\
\hline 2017 & La llamada & $\begin{array}{l}\text { Javier Ambrossi } \\
\text { y Javier Calvo }\end{array}$ & $\begin{array}{l}\text { Javier Ambrossi y Javier Calvo } \\
\text { (disponible en la web de la } \\
\text { Academia de Cine: La llamada })\end{array}$ & Homónimo & $\begin{array}{l}\text { Javier Ambrossi } \\
\text { y Javier Calvo }\end{array}$ \\
\hline 2017 & El guardián invisible & $\begin{array}{c}\text { Fernando González } \\
\text { Molina }\end{array}$ & $\begin{array}{c}\text { Luiso Berdejo } \\
\text { (disponible en la web de la } \\
\text { Academia de Cine: } \\
\text { El guardián invisible) }\end{array}$ & Homónimo & $\begin{array}{l}\text { Dolores } \\
\text { Redondo }\end{array}$ \\
\hline 2017 & El autor & $\begin{array}{l}\text { Manuel Martín } \\
\text { Cuenca }\end{array}$ & $\begin{array}{l}\text { Manuel Martín Cuenca } \\
\text { y Alejandro Hernández } \\
\text { (disponible en la web de la } \\
\text { Academia de Cine: } \underline{\text { El autor })}\end{array}$ & El móvil & Javier Cercas \\
\hline 2017 & Musa & Jaume Balagueró & $\begin{array}{c}\text { Jaume Balagueró y Fernando } \\
\text { Navarro }\end{array}$ & $\begin{array}{c}\text { La dama número } \\
\text { trece }\end{array}$ & $\begin{array}{l}\text { José Carlos } \\
\text { Somoza }\end{array}$ \\
\hline 2017 & $\begin{array}{l}\text { Nur y el Templo del } \\
\text { Dragón (Nur eta } \\
\text { herensugearen } \\
\text { tenplua) }\end{array}$ & $\begin{array}{l}\text { Juan Bautista } \\
\text { Berasategi }\end{array}$ & $\begin{array}{c}\text { Eneko Olasagasti } \\
\text { (disponible en la web de la } \\
\text { Academia de Cine: } \underline{\text { Nur y el }} \\
\text { Templo del Dragón })\end{array}$ & Homónimo & $\begin{array}{c}\text { Toti Martínez de } \\
\text { Lezea }\end{array}$ \\
\hline 2017 & Oro & Agustín Díaz Yanes & $\begin{array}{c}\text { Agustín Díaz Yanes y Arturo } \\
\text { Pérez-Reverte }\end{array}$ & $\begin{array}{l}\text { Homónimo } \\
\text { (inédito) }\end{array}$ & $\begin{array}{l}\text { Arturo Pérez- } \\
\text { Reverte }\end{array}$ \\
\hline 2017 & $\begin{array}{c}\text { Errementari } \\
(\text { El herrero y el diablo) }\end{array}$ & Paul Urkijo Alijo & $\begin{array}{c}\text { Asier Guerricaechevarría } \\
\text { y Paul Urkijo Alijo }\end{array}$ & $\begin{array}{l}\text { Patxi el Herrero: } \\
\text { malvado y } \\
\text { maleante (leyenda } \\
\text { vasca) }\end{array}$ & Anónimo \\
\hline
\end{tabular}




\begin{tabular}{|c|c|c|c|c|c|}
\hline 2017 & $\begin{array}{l}\text { La piel fría } \\
\text { (Cold Skin) }\end{array}$ & Xavier Gens & Eron Sheean y Jesús Olmo & Homónimo & $\begin{array}{l}\text { Albert Sánchez } \\
\text { Piñol }\end{array}$ \\
\hline 2017 & La niebla y la doncella & Andrés Koppel & Andrés Koppel & Homónimo & Lorenzo Silva \\
\hline 2017 & $\begin{array}{c}\text { Tierra firme } \\
\text { (Anchor and Hope) }\end{array}$ & $\begin{array}{l}\text { Carlos Marqués- } \\
\text { Marcet }\end{array}$ & $\begin{array}{c}\text { Carlos Marqués-Marcet y Jules } \\
\text { Nurrish }\end{array}$ & $\begin{array}{l}\text { Maternidades } \\
\text { subversivas }\end{array}$ & María Llopis \\
\hline 2017 & $\begin{array}{l}\text { Incierta gloria } \\
\text { (Incerta glòria) }\end{array}$ & Agustí Villaronga & Agustí Villaronga y Coral Cruz & Homónimo & Joan Sales \\
\hline 2017 & $\begin{array}{l}\text { La higuera de los } \\
\text { bastardos }\end{array}$ & Ana Murugarren & $\begin{array}{c}\text { Ana Murugarren } \\
\text { (disponible en la web de la } \\
\text { Academia de Cine: } \underline{\text { La higuera }} \\
\underline{\text { de los bastardos) }}\end{array}$ & La higuera & Ramiro Pinilla \\
\hline 2017 & $\begin{array}{l}\text { La estación violenta } \\
\text { (A estación violenta) }\end{array}$ & Anxos Fazáns & $\begin{array}{c}\text { Xacobe Casas, Anxos } \\
\text { Fazáns, Daniel Froiz y Ángel } \\
\text { Santos (disponible en la web } \\
\text { de la Academia de Cine: } \\
\text { La estación violenta) }\end{array}$ & Homónimo & Manuel Jabois \\
\hline 2017 & Llueven vacas & Fran Arráez & Carlos Be y Fran Arráez & Homónimo & Carlos Be \\
\hline 2017 & Las heridas del viento & Juan Carlos Rubio & $\begin{array}{c}\text { Juan Carlos Rubio } \\
\text { (disponible en la web de la } \\
\text { Academia de Cine: } \underline{\text { Las heridas }} \\
\underline{\text { del viento })}\end{array}$ & Homónimo & $\begin{array}{l}\text { Juan Carlos } \\
\text { Rubio }\end{array}$ \\
\hline 2017 & M'esperaràs? & Carles Alberola & Carles Alberola & Homónimo & Carles Alberola \\
\hline 2017 & El jugador de ajedrez & Luis Oliveros & Julio Castedo & Homónimo & Julio Castedo \\
\hline 2017 & Yerma & $\begin{array}{l}\text { Emilio Ruiz } \\
\text { Barrachina }\end{array}$ & $\begin{array}{l}\text { Nicholas Aikin, Tirso Calero } \\
\text { y Emilio Ruiz Barrachina }\end{array}$ & Homónimo & $\begin{array}{l}\text { Federico García } \\
\text { Lorca }\end{array}$ \\
\hline 2017 & $\begin{array}{l}\text { Donde el bosque se } \\
\text { espesa }\end{array}$ & $\begin{array}{c}\text { Miguel Ángel Calvo } \\
\text { Buttini }\end{array}$ & $\begin{array}{l}\text { Miguel Ángel Calvo Buttini y } \\
\text { Laila Ripoll }\end{array}$ & $\begin{array}{l}\text { Homónimo } \\
\text { (inédito) }\end{array}$ & $\begin{array}{l}\text { Mariano Llorente } \\
\text { y Laila Ripoll }\end{array}$ \\
\hline 2018 & Tiempo después & José Luis Cuerda & $\begin{array}{l}\text { José Luis Cuerda } \\
\text { (disponible en la web de la } \\
\text { Academia de Cine: } \\
\underline{\text { Tiempo después) }}\end{array}$ & Homónimo & José Luis Cuerda \\
\hline 2018 & El aviso & Daniel Calparsoro & $\begin{array}{c}\text { Chris Sparling, Jorge } \\
\text { Guerricaechevarría y Patxi } \\
\text { Amezcua (disponible en la } \\
\text { web de la Academia de Cine: } \\
\text { El aviso) }\end{array}$ & Homónimo & Paul Pen \\
\hline
\end{tabular}




\begin{tabular}{|c|c|c|c|c|c|}
\hline 2018 & $\begin{array}{l}\text { Buñuel en el laberinto } \\
\text { de las tortugas }\end{array}$ & $\begin{array}{l}\text { Salvador Simó } \\
\text { Busom }\end{array}$ & $\begin{array}{l}\text { Eligio R. Montero y Salvador } \\
\text { Simó Busom (disponible en la } \\
\text { web de la Academia de Cine: } \\
\frac{\text { Buñuel en el laberinto de las }}{\underline{\text { tortugas) }}}\end{array}$ & Homónimo & Fermín Solís \\
\hline 2018 & Sordo & $\begin{array}{l}\text { Alfonso Cortés- } \\
\text { Cavanillas }\end{array}$ & $\begin{array}{l}\text { Alfonso Cortés-Cavanillas } \\
\text { y Juan Carlos Díaz } \\
\text { (disponible en la web de la } \\
\text { Academia de Cine: } \underline{\text { Sordo }} \text { ) }\end{array}$ & Homónimo & $\begin{array}{l}\text { David Muñoz } \\
\text { y Rayco Pulido }\end{array}$ \\
\hline 2018 & Los futbolísimos & $\begin{array}{l}\text { Miguel Ángel } \\
\text { Lamata }\end{array}$ & $\begin{array}{c}\text { Pablo Fernández y Miguel } \\
\text { Ángel Lamata }\end{array}$ & Homónimo & Roberto Santiago \\
\hline 2018 & Ánimas & $\begin{array}{c}\text { Laura Alvea y José } \\
\text { Ortuño }\end{array}$ & $\begin{array}{c}\text { José Ortuño } \\
\text { (disponible en la web de la } \\
\text { Academia de Cine: } \underline{\text { Ánimas) }}\end{array}$ & Homónimo & José Ortuño \\
\hline 2018 & El rey & $\begin{array}{l}\text { Alberto San Juan y } \\
\text { Valentín Álvarez }\end{array}$ & $\begin{array}{c}\text { Alberto San Juan } \\
\text { (disponible en la web de la } \\
\text { Academia de Cine: } \\
\underline{\text { El rey })}\end{array}$ & $\begin{array}{l}\text { Homónimo } \\
\text { (inédito) }\end{array}$ & Alberto San Juan \\
\hline 2018 & $\begin{array}{l}\text { Memorias de un } \\
\text { hombre en pijama }\end{array}$ & Carlos FerFer & $\begin{array}{l}\text { Ángel de la Cruz, Diana López } \\
\text { y Paco Roca (disponible en la } \\
\text { web de la Academia de Cine: } \\
\frac{\text { Memorias de un hombre en }}{\text { pijama })}\end{array}$ & Homónimo & Paco Roca \\
\hline 2018 & No te supe perder & $\begin{array}{l}\text { Manuel Benito de } \\
\text { Valle }\end{array}$ & $\begin{array}{c}\text { Manuel Benito de Valle } \\
\text { y Salvador Navarro }\end{array}$ & Homónimo & Salvador Navarro \\
\hline 2018 & Miau & Ignacio Estaregui & $\begin{array}{l}\text { Ignacio Estaregui (disponible } \\
\text { en la web de la Academia de } \\
\text { Cine: } \underline{\text { Miau }} \text { ) }\end{array}$ & $\begin{array}{l}\text { Hilo musical para } \\
\text { una piscifactoría }\end{array}$ & Juan Luis Saldaña \\
\hline 2018 & Black is Beltza & Fermin Muguruza & $\begin{array}{l}\text { Harkaitz Cano, Fermín } \\
\text { Muguruza y Eduard Solà }\end{array}$ & Homónimo & $\begin{array}{c}\text { Fermin } \\
\text { Muguruza, } \\
\text { Harkaitz Cano } \\
\text { y Jorge Alderete }\end{array}$ \\
\hline 2018 & El año de la plaga & $\begin{array}{l}\text { Carlos Martín } \\
\text { Ferrera }\end{array}$ & $\begin{array}{l}\text { Ángeles Hernández, Miguel } \\
\text { Ibáñez Monroy y David } \\
\text { Matamoros, Marc Pastor }\end{array}$ & Homónimo & Marc Pastor \\
\hline 2018 & $\begin{array}{c}\text { El hijo del } \\
\text { acordeonista } \\
\text { (Soinujolearen semea) }\end{array}$ & Fernando Bernués & Patxo Tellería & Homónimo & Bernardo Atxaga \\
\hline 2018 & $\begin{array}{l}\text { Los habitantes de la } \\
\text { casa deshabitada (TV) }\end{array}$ & Marisa Paniagua & Ramón Paso & Homónimo & $\begin{array}{l}\text { Enrique Jardiel } \\
\text { Poncela }\end{array}$ \\
\hline
\end{tabular}




\begin{tabular}{|c|c|c|c|c|c|}
\hline 2018 & Bernarda & $\begin{array}{l}\text { Emilio Ruiz } \\
\text { Barrachina }\end{array}$ & $\begin{array}{l}\text { Tirso Calero y Emilio Ruiz } \\
\text { Barrachina (disponible en la } \\
\text { web de la Academia de Cine: } \\
\text { Bernarda })\end{array}$ & $\begin{array}{c}\text { La casa de } \\
\text { Bernarda Alba }\end{array}$ & $\begin{array}{c}\text { Federico García } \\
\text { Lorca }\end{array}$ \\
\hline 2018 & Vilafranca (TV) & Lluís María Güell & Jordi Casanovas & Homónimo & Jordi Casanovas \\
\hline 2019 & $\begin{array}{c}\text { Ventajas de viajar en } \\
\text { tren }\end{array}$ & Aritz Moreno & $\begin{array}{c}\text { Javier Gullón (disponible en la } \\
\text { web de la Academia de Cine: } \\
\underline{\text { Ventajas de viajar en tren }} \text { ) }\end{array}$ & Homónimo & Antonio Orejudo \\
\hline 2019 & Legado en los huesos & $\begin{array}{c}\text { Fernando González } \\
\text { Molina }\end{array}$ & $\begin{array}{c}\text { Luiso Berdejo (disponible en la } \\
\text { web de la Academia de Cine: } \\
\text { Legado en los huesos) }\end{array}$ & Homónimo & $\begin{array}{l}\text { Dolores } \\
\text { Redondo }\end{array}$ \\
\hline 2019 & Intemperie & Benito Zambrano & $\begin{array}{l}\text { Pablo Remón, Daniel Remón } \\
\text { y Benito Zambrano (disponible } \\
\text { en la web de la Academia de } \\
\text { Cine: } \underline{\text { Intemperie) }}\end{array}$ & Homónimo & Jesús Carrasco \\
\hline 2019 & $\begin{array}{l}\text { El silencio de la } \\
\text { ciudad blanca }\end{array}$ & Daniel Calparsoro & $\begin{array}{l}\text { Alfred Pérez-Fargas y Roger } \\
\text { Danès (disponible en la web } \\
\text { de la Academia de Cine: } \underline{E l} \\
\text { silencio de la ciudad blanca) }\end{array}$ & Homónimo & $\begin{array}{c}\text { Eva García Sáenz } \\
\text { de Urturi }\end{array}$ \\
\hline 2019 & Gente que viene y bah & Patricia Font & $\begin{array}{c}\text { Darío Madrona y Carlos } \\
\text { Montero }\end{array}$ & Homónimo & Laura Norton \\
\hline 2019 & El silencio del pantano & Marc Vigil & Sara Antuña y Carlos de Pando & Homónimo & Juanjo Braulio \\
\hline 2019 & Litus & Dani de la Orden & $\begin{array}{c}\text { Marta Buchaca (disponible en } \\
\text { la web de la Academia de } \\
\text { Cine: } \underline{\text { Litus) }}\end{array}$ & Homónimo & Marta Buchaca \\
\hline 2019 & Elisa y Marcela & Isabel Coixet & $\begin{array}{c}\text { Isabel Coixet y Narciso de } \\
\text { Gabriel (disponible en la web } \\
\text { de la Academia de Cine: } \underline{\text { Elisa y }} \\
\underline{\text { Marcela })}\end{array}$ & Homónimo & $\begin{array}{c}\text { Narciso de } \\
\text { Gabriel }\end{array}$ \\
\hline 2019 & $\begin{array}{c}\text { ¿A quién te llevarías a } \\
\text { una isla desierta? }\end{array}$ & Jota Linares & Jota Linares y Paco Anaya & $\begin{array}{l}\text { Homónimo } \\
\text { (inédito) }\end{array}$ & Jota Linares \\
\hline 2019 & El plan & Polo Menárguez & 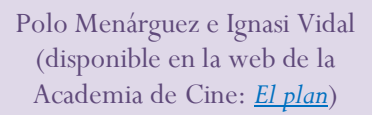 & Homónimo & Ignasi Vidal \\
\hline 2019 & Asamblea & Álex Montoya & $\begin{array}{c}\text { Juli Disla y Jaume Pérez } \\
\text { (disponible en la web de la } \\
\text { Academia de Cine: } \underline{\text { Asamblea }} \text { ) }\end{array}$ & $\begin{array}{l}\text { La gent } \\
\text { (inédito) }\end{array}$ & $\begin{array}{l}\text { Juli Disla } \\
\text { y Jaume Pérez }\end{array}$ \\
\hline
\end{tabular}




\begin{tabular}{|c|c|c|c|c|c|}
\hline 2019 & Eroski Paraíso & $\begin{array}{c}\text { Jorge Coira y Xesús } \\
\text { Ron }\end{array}$ & $\begin{array}{c}\text { Xesús Ron, Miguel de } \\
\text { Lira, Manuel Cortés y Patricia } \\
\text { de Lorenzo }\end{array}$ & Homónimo & $\begin{array}{c}\text { Chévere } \\
\text { (compañía de } \\
\text { teatro) }\end{array}$ \\
\hline 2019 & $\begin{array}{l}\text { La vida sin Sara } \\
\text { Amat (La vida sense } \\
\text { la Sara Amat) }\end{array}$ & Laura Jou & Coral Cruz & Homónimo & Pep Puig \\
\hline 2019 & $\begin{array}{c}\text { La estrategia del } \\
\text { pequinés }\end{array}$ & Elio Quiroga & $\begin{array}{l}\text { David Muñoz y Elio Quiroga } \\
\text { (disponible en la web de la } \\
\text { Academia de Cine: } \underline{L a} \\
\text { estrategia del pequinés) }\end{array}$ & Homónimo & Alexis Ravelo \\
\hline 2019 & $\begin{array}{l}\text { La mujer del siglo } \\
\text { (La dona del segle) } \\
\text { (TV) }\end{array}$ & Silvia Quer & $\begin{array}{c}\text { Margarita Melgar y Ana Sanz } \\
\text { Magallón }\end{array}$ & Homónimo & Margarita Melgar \\
\hline 2020 & Orígenes secretos & David Galán & $\begin{array}{c}\text { David Galán y Fernando } \\
\text { Navarro (disponible en la web } \\
\text { de la Academia de Cine: } \\
\text { Orígenes secretos) }\end{array}$ & Homónimo & David Galán \\
\hline
\end{tabular}

Sánchez Salas (disponible en la

2020 Los europeos Víctor García León

web de la Academia de Cine:

Homónimo Rafael Azcona

Los europeos)

\begin{tabular}{|c|c|c|c|c|c|}
\hline 2020 & Sentimental & Cesc Gay & Cesc Gay & $\begin{array}{l}\text { Los vecinos de } \\
\text { arriba (inédito) }\end{array}$ & Cesc Gay \\
\hline 2020 & El inconveniente & Bernabé Rico & $\begin{array}{c}\text { Bernabé Rico y Juan Carlos } \\
\text { Rubio }\end{array}$ & $100 \mathrm{~m}^{2}$ & $\begin{array}{l}\text { Juan Carlos } \\
\text { Rubio }\end{array}$ \\
\hline 2020 & Ofrenda a la tormenta & $\begin{array}{l}\text { Fernando González } \\
\text { Molina }\end{array}$ & $\begin{array}{c}\text { Luiso Berdejo } \\
\text { (disponible en la web de la } \\
\text { Academia de Cine: } \\
\text { Ofrenda a la tormenta) }\end{array}$ & Homónimo & $\begin{array}{l}\text { Dolores } \\
\text { Redondo }\end{array}$ \\
\hline 2020 & Malnazidos & $\begin{array}{l}\text { Jaime Marqués } \\
\text { y Cristian Conti }\end{array}$ & $\begin{array}{c}\text { Javier Ruiz Caldera y Alberto } \\
\text { de Toro }\end{array}$ & $\begin{array}{l}\text { Noche de difuntos } \\
\text { del } 38\end{array}$ & $\begin{array}{l}\text { Manuel Martín } \\
\text { Ferreras }\end{array}$ \\
\hline 2020 & $\begin{array}{l}\text { Campanadas a muerto } \\
\text { (Hil Kanpaiak) }\end{array}$ & Imanol Rayo & $\begin{array}{l}\text { Joanes Urkixo (disponible en } \\
\text { la web de la Academia de cine: } \\
\text { Campanadas a muerte) }\end{array}$ & 33 ezkil & $\begin{array}{l}\text { Miren } \\
\text { Gorrotxategi }\end{array}$ \\
\hline 2020 & $\begin{array}{l}\text { Enjambre } \\
\text { (Erlauntza) }\end{array}$ & Mireia Gabilondo & Kepa Errasti & $\begin{array}{l}\text { Homónimo } \\
\text { (inédito) }\end{array}$ & Kepa Errasti \\
\hline 2020 & Isaac & $\begin{array}{l}\text { Ángeles Hernández } \\
\text { y David Matamoros }\end{array}$ & $\begin{array}{l}\text { Ángeles Hernández, David } \\
\text { Matamoros y Antonio } \\
\text { Hernández Centeno }\end{array}$ & $\begin{array}{l}\text { El día que nació } \\
\text { Isaac (inédito) }\end{array}$ & $\begin{array}{l}\text { Antonio } \\
\text { Hernández } \\
\text { Centeno }\end{array}$ \\
\hline
\end{tabular}




\begin{tabular}{|c|c|c|c|c|c|}
\hline 2020 & $\begin{array}{c}\text { El crédito (El crèdit) } \\
(\mathrm{TV})\end{array}$ & $\begin{array}{l}\text { Joan Riedweg } \\
\text { y Abel Folk }\end{array}$ & Jordi Galcerán y Ramón Paso & Homónimo & Jordi Galcerán \\
\hline 2020 & La suite nupcial & Carlos Iglesias & $\begin{array}{l}\text { Carlos Iglesias (disponible en } \\
\text { la web de la Academia de } \\
\text { Cine: } \underline{\text { La suite nupcial) }}\end{array}$ & Homónimo & Carlos Iglesias \\
\hline
\end{tabular}

\section{Bibliografía CITADA}

Heredero, Carlos F. y Antonio Santamarina (2008), Biblioteca del cine español, Madrid, Cátedra.

JAIME, Antoine (2000), Literatura y cine en España (1975-1995), Madrid, Cátedra.

Malpartida TiRADO, Rafael (2015), «Subjetividad y adhesión emocional en dos adaptaciones de la novela al cine: La flaqueza del bolchevique y Caníbal de Manuel Martín Cuenca», Signa, 24, págs. 125-148.

PARDO GARCía, Pedro Javier (2011), «Cine, literatura y mito: Don Quijote en el cine, más allá de la adaptación», Arbor, 748, págs. 237-246.

PÉREZ BOWIE, José Antonio (2004), Cine, literatura y poder. La adaptación cinematográfica durante el primer franquismo (1939-1950), Salamanca, Librería Cervantes.

PÉrez Bowie, José Antonio y Fernando GonZÁlez GARcía (2010), El mercado vigilado. La adaptación en el cine español de los 50, Murcia, Tres Fronteras.

PÉrez BowIE, José Antonio (ed.) (2010), La noche se mueve. La adaptación en el cine del tardofranquismo, Madrid, Catarata.

STAM, Robert (2014), Teoría y práctica de la adaptación, México, UNAM.

ZECCHI, Barbara (2012), «Introducción. La adaptación multiplicada», en B. Zecchi (ed.), Teoría y práctica de la adaptación fílmica, Madrid, Editorial Complutense. 